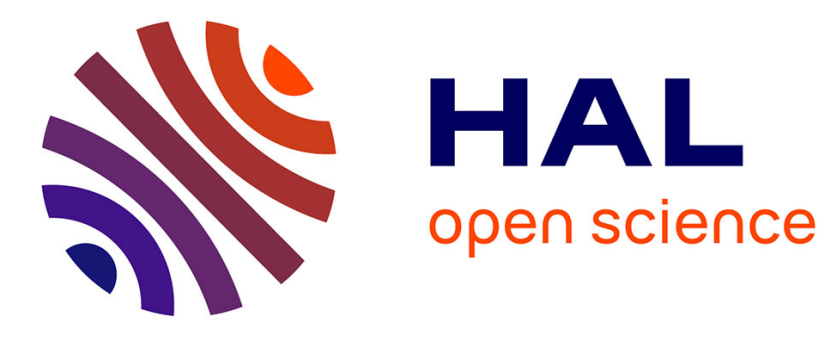

\title{
The Scale Effect of Roughness on Hydrodynamic Contact Friction
}

\author{
Ibrahim Demirci, Sabeur Mezghani, Mohammed Yousfi, Hassan Zahouani, \\ Mohamed El Mansori
}

\section{- To cite this version:}

Ibrahim Demirci, Sabeur Mezghani, Mohammed Yousfi, Hassan Zahouani, Mohamed El Mansori. The Scale Effect of Roughness on Hydrodynamic Contact Friction. The Scale Effect of Roughness on Hydrodynamic Contact Friction, 2012, 55, pp.705-712. 10.1080/10402004.2012.694990 . hal00881208

\section{HAL Id: hal-00881208 \\ https://hal.science/hal-00881208}

Submitted on 28 Jan 2014

HAL is a multi-disciplinary open access archive for the deposit and dissemination of scientific research documents, whether they are published or not. The documents may come from teaching and research institutions in France or abroad, or from public or private research centers.
L'archive ouverte pluridisciplinaire HAL, est destinée au dépôt et à la diffusion de documents scientifiques de niveau recherche, publiés ou non, émanant des établissements d'enseignement et de recherche français ou étrangers, des laboratoires publics ou privés. 


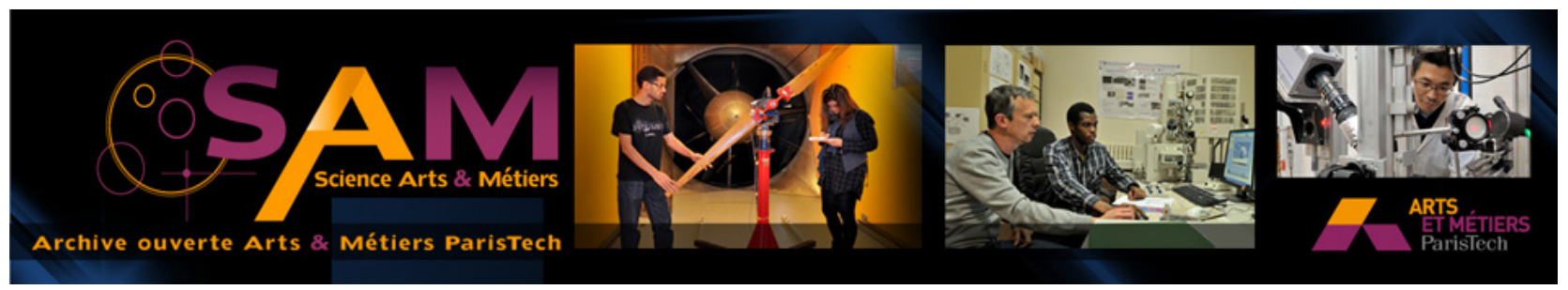

Science Arts \& Métiers (SAM)

is an open access repository that collects the work of Arts et Métiers ParisTech researchers and makes it freely available over the web where possible.

This is an author-deposited version published in: http://sam.ensam.eu

Handle ID: .http://hdl.handle.net/10985/7477

\section{To cite this version :}

Ibrahim DEMIRCI, Sabeur MEZGHANI, Mohammed YOUSFI, Hassan ZAHOUANI, Mohamed EL MANSORI - The Scale Effect of Roughness on Hydrodynamic Contact Friction - Tribology Transactions - Vol. 55, p.705-712 - 2012 


\title{
The Scale Effect of Roughness on Hydrodynamic Contact Friction
}

\author{
I. DEMIRCI, ${ }^{1}$ S. MEZGHANI, ${ }^{1}$ M. YOUSFI, ${ }^{1,2}$ H. ZAHOUANI, ${ }^{3}$ and M. EL MANSORI ${ }^{1}$ \\ ${ }^{1}$ Arts et Métiers Paristech, LMPF \\ Rue Saint Dominique, BP 508, 51006 \\ Chatons en Champagne, France \\ ${ }^{2}$ Renault s.a.s, Direction de l'Ingénierie Mécanique \\ 67 rue des bons raisins, 92500 \\ Rueil Malmaison, France \\ ${ }^{3}$ Laboratoire de Tribologie et Dynamique des Systèmes \\ UMR CNRS 5513, Fcole Centrale de Lyon \\ 36 avenue Guy de Collongue, 69131 \\ Ecully Cedex, France
}

\begin{abstract}
Multistage abrasive finishing processes (grinding, polishing, honing, etc.) are commonly used to produce the geometrical properties of a surface to meet its technical functionalities in the operating characteristics of contacting parts in friction, relating to their durability and reliability (running-in performance, wear resistance, load-carrying capacity, etc.). Coarse abrasive grits followed progressively finer ones are used, which leads to a multiscale stratified surface texture.

In this article, a numerical model of elastohydrodynamic (EHD) contact coupled to a multiscale surface texture model was developed that allows tracking the scale effect of surface features and their interactions on friction performance and lubricant flow under hydrodynamic lubrication conditions. Because the simulation model has as an input the surface topography and to overcome the variability in surface finish formation, textured surfaces at different stages of the finishing process were simulated (virtual texturing method). Surface topography can be decomposed into two principal components: superficial roughness and valleys. Superficial roughness was modeled using a fractal model and a scaling factor was introduced to model valley patterns. The results show the relationship between friction and surface scales.
\end{abstract}

\section{KEY WORDS}

Roughness Scale; Surface Texture; Elastohydrodynamic Lubrication; Friction

\section{INTRODUCTION}

To improve the tribological performance of mechanical components, such as load capacity, wear resistance, and friction coef- ficient, surface texturing is considered as a viable option in surface enpineering. It consists of forming a reasonable texture on the surface. Different mechanisms are usually used to explain this improvement:

- Microhydrodynamic bearing by generation of additional hydrodynamic pressure to increase load-carrying capacity (Hamilton, et al. (I))

- Microreservoirs for the lubricant in cases of starved lubrication (Hamilton, et al. (I))

- A debris reservoir that allows trapping fragments to prevent surface wear

Various forms and techniques of texturing have been developed to generate a surface texture and improve tribological performance. The most common and earliest application of surface texturing consist of surface finishing processes such as grinding, honing, polishing, turning, shaving, and dimpling. More recently, various techniques such as ion beam texturing, etching techniques, and laser texturing have been employed. They are able to generate a deterministic and more controllable texture (Etsion (2)).

The principal statistical parameters of roughness, such as variances in height, slope, and curvature, are scale dependent (Fuller and Tabor (3); Mezghani, et al. (4)). Instruments with different resolutions and scan lengths yield different values of these statis. tical parameters for the same surface. Therefore, it is important to characterize rough surfaces by intrinsic parameters that are independent of the sampling length or area (Fuller and Tabor (3))

The scale effect has been well studied for elastic, elastoplas. tic, and plastic contacts between rough surfaces (Zahouani, et al (5); Majunder and Bhushan (6); Ju and Farris (7)) but not for lubricated contacts under hydrodynamic and elastohydrodynamic (EHD) conditions.

For example, fractal geometry has been widely used in recent years and was applied to characterize surface topography and 
NOMENCLATURB

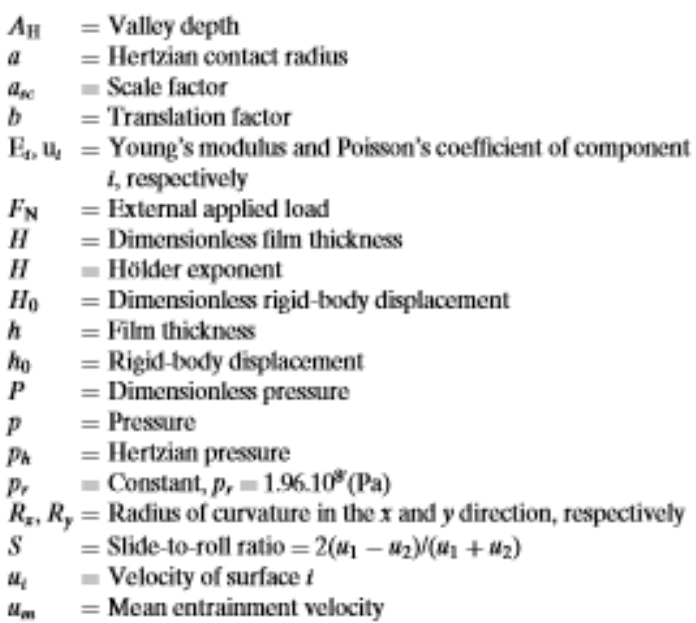

$\mathrm{E}_{\mathrm{t}}, \mathrm{u}_{\mathrm{L}}=$ Young's modulus and Poisson's coefficient of component $i$, respectively

$w \quad=$ Value of Z-component of the displacement vector

$X, Y=$ Dimensionless space coordinates

$x, y, z=$ Space coordinates

$Z \quad=$ Surface topography

$z_{r}=$ Pressure viscosity index (Roelands), $z r=p, c w\left[\ln \left(m_{0}\right)+9.67\right]$

$=$ Pressure-viscosity coefficient

- Flastic deflection of the contacting bodies

$=$ Dimensionless elastic deflection of the contacting. bodies

- Viscosity (Pa.s)

$=$ Dimensionless viscosity $(=\eta / m)$

$=$ Effective viscosities

$=$ Ambient temperature zero-pressure viscosity (Pa.s)

$=$ Friction coefficient

$=$ Lubricant density

$=$ Dimensionless lubricant density

= Ambient temperature and pressure density

$=$ Dimensionless mean shear stress

$=$ Eyring stress $(\mathrm{Pa})$

- Shear stress acting on the surface $(\mathrm{Pa})$

$=$ Second derivative of Gaussian function contact mechanies (Ju and Farris (7); Liu, et al. (8); Gagnepin and Rogues-Carmes (9); Majunder and Tien (10)).

In the hydrodynamic regime, studies have focused primarily on the effect of anisotropy (Ajayi, et al. (11); Mezquani, et al. (12)), shapes and repartitions (Yu, et al. (13); Nanbu, et al. (14)), and deterministic asperities (Siripuram and Stephens (15)) of the textured surfaces. A majority of these studies have focused on surfaces achieved by laser surface texturing. The effects of roughness have been studied in an EHD regime. In particular, the effects of valleys and peaks were studied during the $1990 \mathrm{~s}$ and $2000 \mathrm{k}$. For transverse roughness in line contacts, Greenwood and Morales-Espejel (16) studied pressure and local film fluctuation. In general, surface roughness components deform differently (Lugt and Morales-Espejel (17)) and some authors have investipated the amplitude reduction of transverse and longitudinal roughness (Wang, et al. (18); Venner and Lubrecht (19)). Rough surface topography and orientation were also investigated in mixed lubrication (Zhu and $\mathrm{Hu}(20)$ ). Friction was not discussed in any of these studies. The reduction in friction with partial laser surface texturing (Ryk and Etsion (2l); Ftsion, et al. (22)), transitions in the lubrication regime (Kovalchenko, et al. (23)), and the effectson thin EHD lubrication films (Krupka and Hart (24)) have been studied experimentally. In numerical analyses, it is common to use the concept of virtual texturing technology (Wang and Zhu (25)), which consists of producing surfaces numerically and solving the Reynolds equation. Different patterns and shapes can be studied using this technique. For example, the influence of geometrical shape effects $\mathrm{Yu}$, et al. (13)), microtextures in conformal contacts (Nanbu, et al. (14)), and waviness amplitudes and different roughness orientations on pressure distribution ( $\mathrm{Ai}$ and Cheng (26)) has been investigated.

However, none of these studies considered the scale effect. A global characterization of the area was used, which is considered unsuitable for a surface obtained through various stapes of finishing and thus has a multiscale struc ture (Chen, et al. (27); Sannaredy, et al. (28); Sabri, et at. (29)).

In this article, the scale effects of roughness on friction in an elastohydrodynamic lubrication (EHL) regime were studied. To this aim, a numerical model was developed and a virtual texturinge method was adopted. An advanoed surface characterization was performed based on the decomposition of the surface topography into its two principal elements: superficial roughness (related to friction and wear) and valleys (related to lubricant circulation and reservoirs). These numerical surfaces were used on the numerical EHL contacts.

\section{DESCRIPTION OF THE ELASTOHYDRODYNAMIC MODEL}

A numerical model was developed to estimate the friction generated between rough surfaces. It takes into account the real topography of the surfaces. The scope of this model is to qualitatively predict the friction coefficient obtained when the groove characteristics of surfaces are varied in order to optimizo performance.

\section{Elastohydrodynamic Equations}

The following dimensionless isothermal Reynolds equations (Reynokls (30)) were used to estimate the pressure distribution, film thickness, and friction coefficient. Effective viscosities are introduced to account for the effects of non-Newtonian lubricant behavior.

$$
\frac{\partial}{\partial X}\left(\frac{\bar{\rho} H^{3}}{\lambda \bar{r}} \frac{\partial P}{\partial X}\right)+\frac{\partial}{\partial Y}\left(\frac{\bar{\rho} H^{3}}{\lambda \bar{r}} \frac{\partial P}{\partial Y}\right)=\frac{\partial \bar{\rho} H}{\partial X}
$$

The following boundary condition $P=0$ and cavitation condition $P(X, Y) \geq 0 \vee X, Y$ must be satisfied. To ensure this condition, 
the Reynolds-Swift model was used. In this equation, $\lambda$ is equal to $\frac{13 \text { your }}{e^{x}}$ and $\bar{r}$ is the effective viscosity. Considering that the variation in viscosity along the $z$-direction can be ipnored, the ef fective viscosity can be calculated considering the shear-thinning effect:

$$
\frac{1}{\bar{\eta}}=\frac{1}{\eta} \frac{1}{\overline{\tau_{m}}} \sinh \left(\overline{\tau_{m}}\right)
$$

with $\bar{r}_{m}=\frac{n_{1}}{1}$ where $r_{0}$ is a reference shear stress and $r_{1}$ is the shear stress acting on the surface.

The lubricant's viscosity and density were assumed to be dependent on pressure, and we used the Dowson and Higginson formula (Dowson and Higginson (31); Eq. [3]) and Roelands law (Roelands (32); Eq. [4]):

$$
\bar{\rho}(P)=\left[1+\frac{0.6 \times 10^{-9} P p_{h}}{1+1.7 \times 10^{-9} P p_{h}}\right]
$$

where $\rho_{0}$ is the density at ambient pressure.

$$
\bar{\eta}(P)=\exp \left(\left(\operatorname{In}\left(\boldsymbol{x}_{0}\right)+9.67\right)\left(-1+\left(1+\frac{P \cdot p_{k}}{p_{r}}\right)^{\bar{D}}\right)\right),
$$

where $m$ is the viscosity at ambient pressure, $p_{r}$ is a constant equal to $1.96 \times 10^{3}$, and $z$, is the pressure viscosity index.

The film thickness equation is piven in dimensionless form by the following equation:

$$
H(X, Y)=H_{0}+\frac{X^{2}}{2}+\frac{Y^{2}}{2}+\xi(X, Y)-Z(X, Y)
$$

$Z$ is the height of the liner surface topography at each position $(X, Y)$ and $\delta(X, Y)$ is the dimensionless surface deformation calculated by

$$
\bar{\delta}(X, Y)=\frac{2}{\pi^{2}} \iint_{\mathrm{R}} \frac{P\left(X^{\curvearrowright}, Y\right) d X^{3} d Y}{\sqrt{\left(X-X^{\prime}\right)^{2}}+\left(Y-Y^{2}\right)^{2}}
$$

The global force balance condition is given by:

$$
\frac{2 \pi}{3}=\iint_{\Omega} P(X, Y) d X d Y
$$

TABIR 1 - COMPARISON OFTHR CURRFNT MODEI WTTH CHAPKoV's MODEL_. (37)

\begin{tabular}{lcc}
\hline & Chapkov (37) & Carrent Model \\
\hline Central oll film thickness $H_{c}$ & 0.05811 & 0.057 \\
Minimum oil film thickness $H_{m}$ & 0.0280 & 0.0279 \\
\hline
\end{tabular}

\section{Numerical Procedure}

In order to obtain the film pressure distribution, the Reynolds equation was solved using a finite difference method. A separate second-order backward scheme was used because it was the bet ter scheme (Liu, et al. (33)) was used. The discretized equation was solved using Jacobi line relaxation (Venner and Lubrecht (34)). The full-scale mixed EHL approach developed by Hu and Zhu (35) was used in the present work. Fither a multigrid method (Venner and Lubrecht (34)) or progressive mesh densification technique (Zhu (36)) was used in order to accelerate solution convergence. Elastic deformation calculation was conducted using the discrete convolution and fast Fourier transform method develoged by Liu, et al. (8). The solution domain was determined as $-2.5 \leq X \leq 1.5$ and $-2.0 \leq X \leq 2.0$. The computational grid covering the domain consisted of $512 \times 512$ or $1,024 \times 1,024$ nodes equally spaced.

\section{Model Validation}

The present model in a fully flooded smooth contacts case was compared to the non-Newtonian simulation done by Chapkov (37). Table 1 provides the dimensionless central and minimum oil film thickness for the following dimensionless Moes and Venner parameters $M=500$ and $L=20$. The difference between our model and Chapkov's (37) work was less than $2 \%$. This comparison confirmed the validity of the model presented in this article.

The mixed lubrication approach of our model was compared to the sinusoidal wavy surface case in Hu and Zhu's (35) work. The same parameter and rolling velocity of $312.5 \mathrm{mms}^{-1}$ was chosen. Figure 1 shows the pressure profile and film thickness vs. the

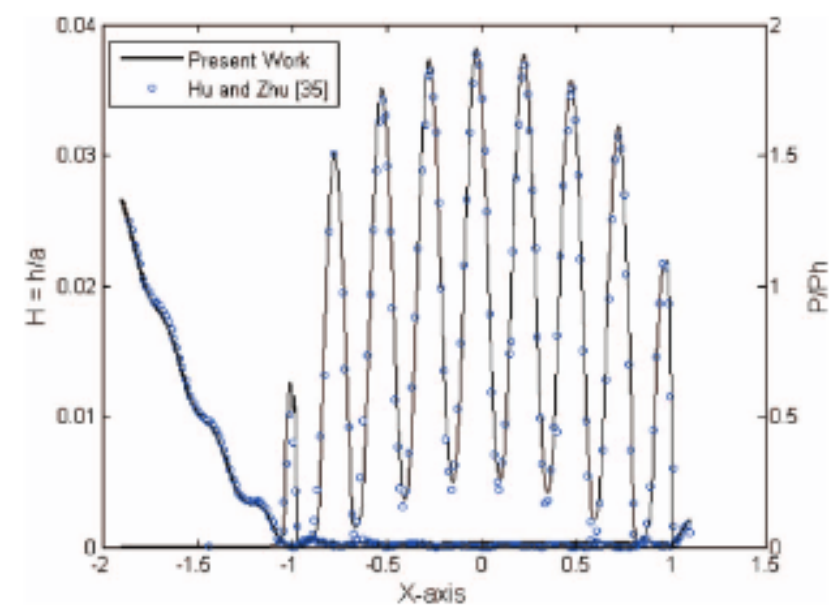

Fig. 1-Film thickness and pressure profile of the present work compared to Hu and Zhu's work (35). (color figure available online.) 
$X$ axis. Good agreement was found between the two models. This test confirmed the validity of the model presented in this article.

\section{MULTISCALE SURFACES CHARACTERIZATION AND SYNTHESIS TEXTURE MODEL}

Finished surfaces are typically machined by more than one manufacturing process. The resulting surface topography exhibits topographical features over a wide range of scales from the nanoto microscale that are superimposed on each other and located at different positions on the surface. In relation to their wet contact functions, they are penerally decomposed into three elements reference surfaces (waviness and form); plateaus (related to fric tion and wear); and valleys (related to lubricant circulation and reservoirs; Decenciere and Jeulin (38)). These elements play different roles in a wet contact. The superficial roughness of the plateau component plays an important role with respect to load carrying capacity and friction, whereas the valleys serve as lubri cant reservoirs and distribution circuits. Therefore, they can be analyzed separately (Decenciere and Jeulin (38)).

To identify the scale effect of the surface features, a math ematical model of each surface roughness component (plateaus and valleys) is presented.

\section{Fractal Model of Superficial Surface Irregularities} (Plateau Component)

The details of $Z(x)$ depend on the length scale; each $Z(x)$ was assumed to be a continuous but nondifferentiable function. This means that the presence of any small roughness elements may prevent us from reaching a satisfactory limit of

$$
\frac{(Z(x+\Delta)-Z(x))}{\Delta} \text { as } \Delta \rightarrow 0
$$

A simple way to obtain this behavior for a function $Z(x)$ is to assume that the increment of $Z(x)$ is related to $\Delta$ by the selfaffinity relation:

$$
|Z(x+\Lambda)-Z(x)| \propto \Lambda^{N}, 0<H<1 \Lambda \rightarrow 0
$$

$\lim _{\Lambda \rightarrow 0} \Lambda^{H-1}$ only exists if $H=1$. The derivative of $Z$ is proportional to the limit.

For $0<H<1$, this derivative is infinite, although the function remains continuous, and for $H=0$ the function itself becomes discontinuous. So by varying from 0 to 1 , the parameter $H$ characterizes the transition from a noncontinuous to differentiable function, and the range $0<H<1$ corresponds to nondifferentiable functions that become smoother as $H$ increases. Thus, $H$ can be considered as an indicator of roughness (Merghani, et al. (4)). Because we are concerned with functions that can be considered to represent random processes, the self-affinity relation can be expressed in terms of variance in the increments of $\mathrm{Z}$ :

$$
\left|(Z(x+\Delta)-Z(x))^{2}\right| \alpha \Delta^{\mathscr{W}}, 0<H<1 \Lambda \rightarrow 0
$$

For random rough surfaces, the random displacement method provides one of the simplest algorithms to generate random fractal surfaces. For analysis proposes, it is particularly useful to have a numerical tool that creates the same kind of morphological data arrays that most scanning acquisition methods for real range im ages create, namely, an $x, y$ array of $Z$ values: $Z(x, y)$. The algorithm for a randlom displacement method of rough surfaces is de scribed in Mezshani, et al. (4), Felder (39), and Mandelbrot and Van Ness (40)

In order to study the influence of the Hoider exponent of roughness on the friction parameter we propose generating rough surfaces parameterized in roughness by their Holder exponent. Each of those surfaces is generated by the random displacement model. Figure 2 shows the construction of three surfaces with different Holder exponents, $H=0.1, H=0.5, H=0.8$. The surfaces generated were put into an elastic hydrodynamic contact under a pressure of $500 \mathrm{MPa}$ with a rigid plane.

\section{Multiscale Model of Surface Groove Patterns (Valley Component)}

The honed surfaces were generated by successive honing processes stages using increasingly finer abrasive grains. Honed surfaces are composed of profound valleys (lubrication reservoirs) and finer valleys (to reduce the contact area and friction). The scale effect is studied only for the finer valleys because they affect friction.

A multiscale model describing, the essential characteristics of the finer valley patterns was developed. In this model, valley features (Fig. 3b) were modeled by the following $S$, function:

$$
S_{\eta}(x)= \begin{cases}\psi_{\psi_{x}, b} & k_{w_{1}, b}<0 \\ 0 & k_{,}, b \geq 0\end{cases}
$$

where $\psi_{x}, b(x)$ is the second derivative of the Gaussian function (Fig. 3a) defined by

$$
\text { *., } b(x)=A_{H}\left(1-r^{2}\right) e-r^{20}
$$

$r=\frac{(x-b)}{a_{z}}, b$ corresponds to the feature valley position, and $a_{s c}$ is the scale factor.

The modeled valley surface component takes into acount the scale parameter $a_{s c}$ and the depth amplitude $A_{\mu}$ as variables. To study the scale effect of this surface component, various surfaces were generated with varying $A_{\mathrm{H}}$ in the range of 0.3 to $2.1 \mu \mathrm{m}$ and $a_{s c}$ from 7.5 to $19 \mu \mathrm{m}$. To more closely match realistic generated surfaces, two profound valleys with the coupled parameters $\left(A_{\mathrm{H}}\right)_{\max }=3 \mu \mathrm{m}$ and $\left(a_{\mathrm{kc}}\right)_{\max }=25 \mu \mathrm{m}$ were added for each simulated surfaces.

Note that the effect of surface anisotropy is well known (Ai and Cheng (26)) and is not taken into account in this study. All grooves were oriented perpendicular to the sliding direction.

A spatial sampling step of $2 \mu \mathrm{m}$ was chosen. The total sampling area was therefore approximately $1,024 \mathrm{~mm} \times 1,024 \mathrm{~mm}$. Examples of the virtual surface with different values of $a_{s c}$ and $A_{\text {H }}$ are presented in Fig. 4.

\section{RESULTS AND DISCUSSION \\ Multiscale Effect of Roughness Irregularities (Plateau Component)}

The sliding velocities varied between 2 and $52 \mathrm{~ms}^{-1}$ for each of the four surfaces with different Holder exponents. The other parameters are shown in Table 2. The second surface was fixed. An isothermal model was used in the present work for simplicity; however, in pure sliding cases thermal effects are expected to have a significant impact on the frictional behavior of these 


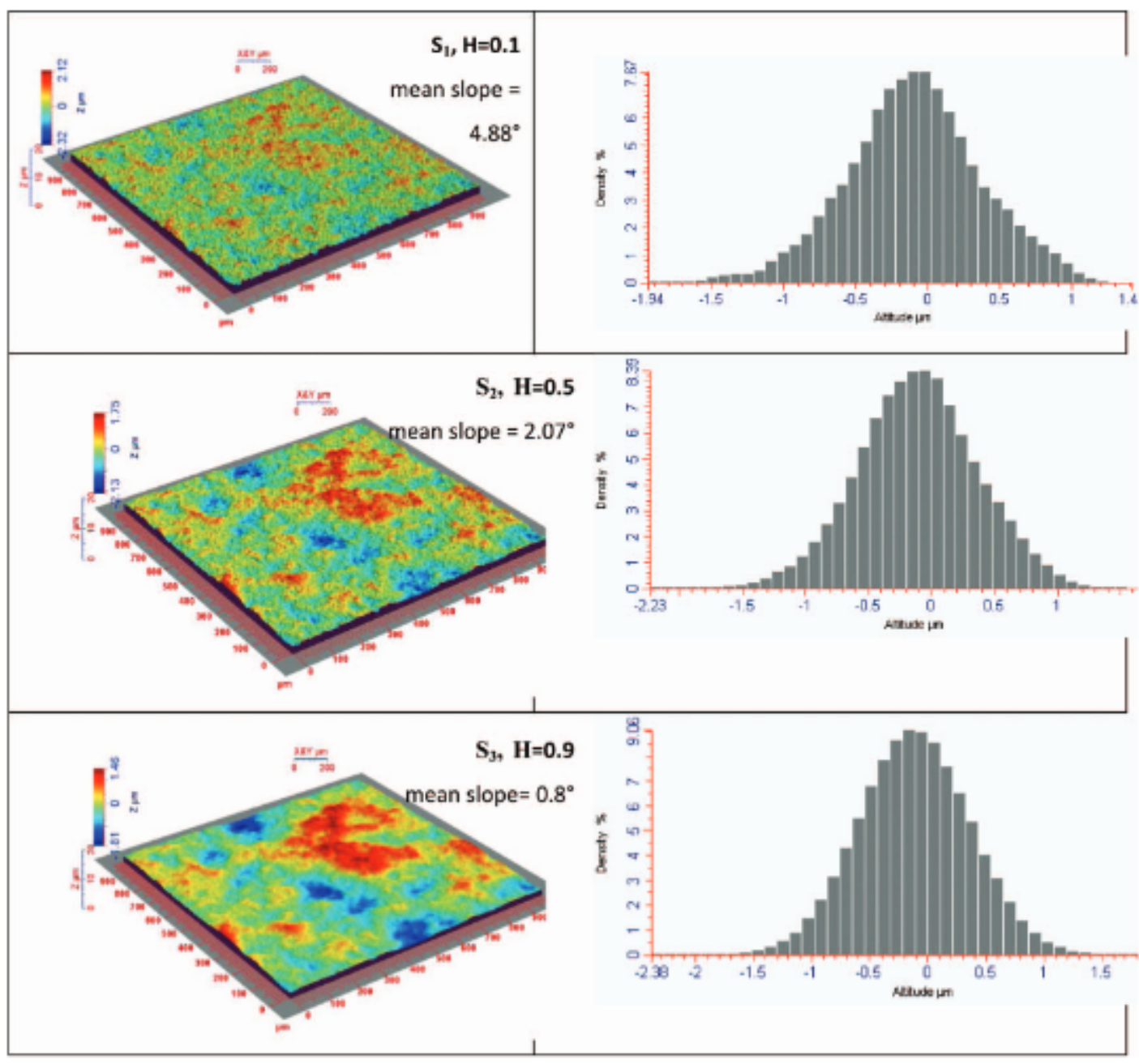

Fig. 2-Statistical self-affine surfaces with the same roughness amplitude $\left(R_{a}=0.48 \mu \mathrm{m}\right)$ and different Hölder dimension $H$ : (a) 0.1 , (b) 0.5 , and (c) 0.9 . (coler figure avallable online.)
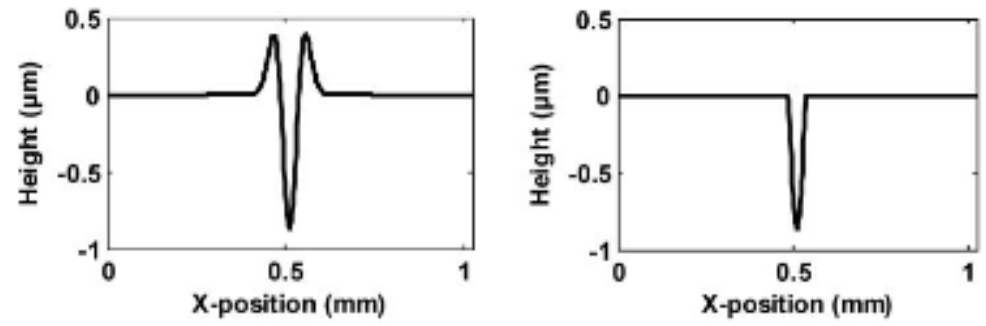

Fig. 3- (a) asc,b Second derivative of Gaussian function (DoG2) and (b) S, valley feature (groove pattern). 

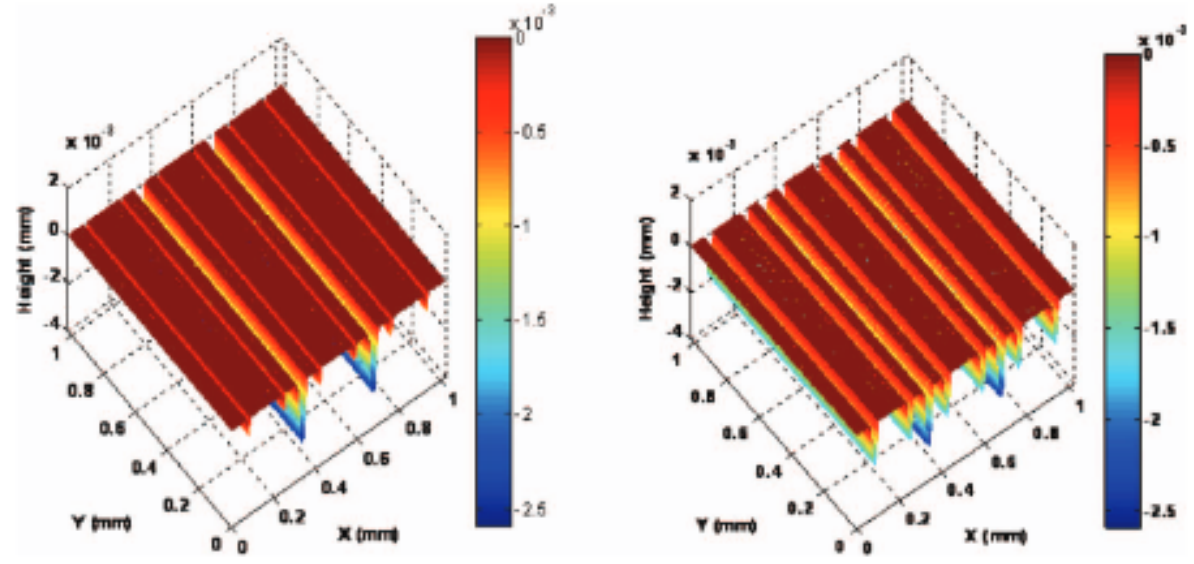

Fig. 4- Examples of surface valley component with different ( $A_{n,}, a_{c s}$ ) parameters: (a) $A_{n 1}=0.9 \mu \mathrm{m}, a_{c c}=7.5 \mu \mathrm{m}$; (b) $A_{n 1}=21 \mathrm{\mu m}, a_{c c}=17.5 \mu \mathrm{m}$. (color figure available online.)

contacts. However, qualitative comparison should also be done to study the influence of the Holder exponent on the friction coefficient.

Using the calculated pressure field, the friction coefficient was determined by the following equation:

$$
\mu=\frac{\tau_{0} \iint_{\Omega} \overline{\tau_{m}}(X, Y) d X d Y}{p_{h} \iint_{\Omega} P(X, Y) d X d Y}
$$

Figure 5 shows the friction coefficient as a function of mean entrainment velocities for surfaces with different Holder exponents $(H)$. The smaller $H$ is, the more irregular the surface is. For all surfaces, the friction coefficient decreased until a minimum value and increased when velocity increased. The results of this study show that the local scale of roughness modified the distribution of the contact pressure and friction. This clearly shows the influence of the fractal dimension of roughness on the friction coefficient in a wide range of sliding velocities. Two trends are visible in the Fig. 5. For low velocity, the friction coefficient is high for low Holder exponents. In other words, when the surface becomes more irregular, the friction coefficient increases. In this case, some asperity contacts appear: the mixed lubrication case is encountered. The more irregular the surface is (low $H$ ), the higher the friction coefficient is. In this situation, the contact surface increases when $H$ decreases, which results in more asperity contacts, yielding a high coefficient friction.

Furthermore, for the elastohydrodynamic case (high velocity), the friction coeflicient increased with sliding speed. The friction

TABLE 2-OPERATING CONDTIONS AND LUBRICANT PROFERTIES

\begin{tabular}{lccc}
\hline Parameter & Value & Parameter & Valuc \\
\hline$F_{\mathrm{N}}(\mathrm{N})$ & 500 & $\alpha\left(\mathrm{GPa}^{-1}\right)$ & 22.00 \\
$\mu_{\mathrm{m}}\left(\mathrm{ms}^{-1}\right)$ & 4.0 & $R_{x}(\mathrm{~m})$ & 0.4 \\
$\mu_{0}(\mathrm{~Pa} . \mathrm{s})$ & 0.04 & $E_{\mathrm{j}}(\mathrm{GPa})$ & 210 \\
$u$ & 0.3 & & \\
\hline
\end{tabular}

coefficient increased when the Hoilder exponent increased; that is, with a smoother surface. This indicates that the scale of superficial roughness irregularity has a beneficial effect on friction in a hydrodynamic regime. Rough surfaces engender (microbydrodynamic bearing) to increase load-carrying capacity, which improves the friction coefficient (Etsion (2); Yu, et al. (13); Nanbu, et al. (14); Thu and Hu (20); Kovakchenko, et al. (23); Krupka and Hart (24)).

\section{Multiscale Effect of Surface Grooves (Valley Component)}

The influence of the two parameters of the surface valleys texturing model (scale factor $a_{n c}$ and valley depth $A_{H}$ ) was studied.

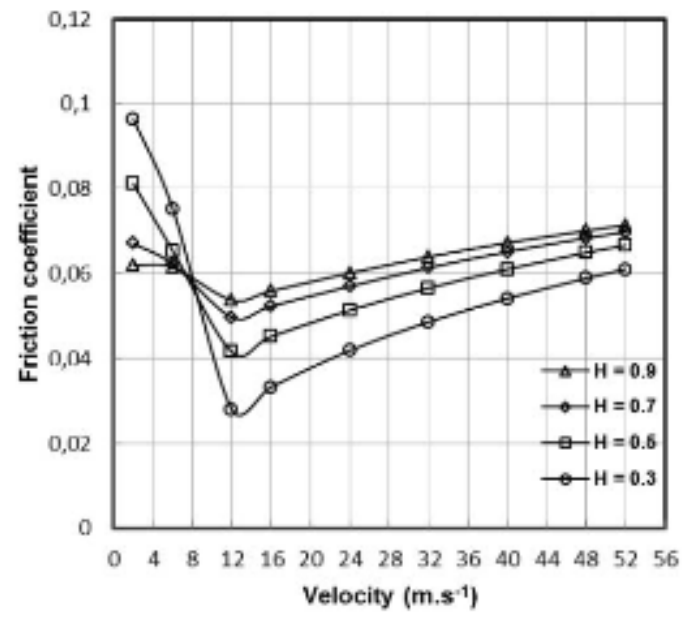

Fig. 5 - Friction coefficient vs Hölder exponent for different velocities in the range of 2 to $52 \mathrm{~m} \cdot \mathrm{s}^{-1}$. 

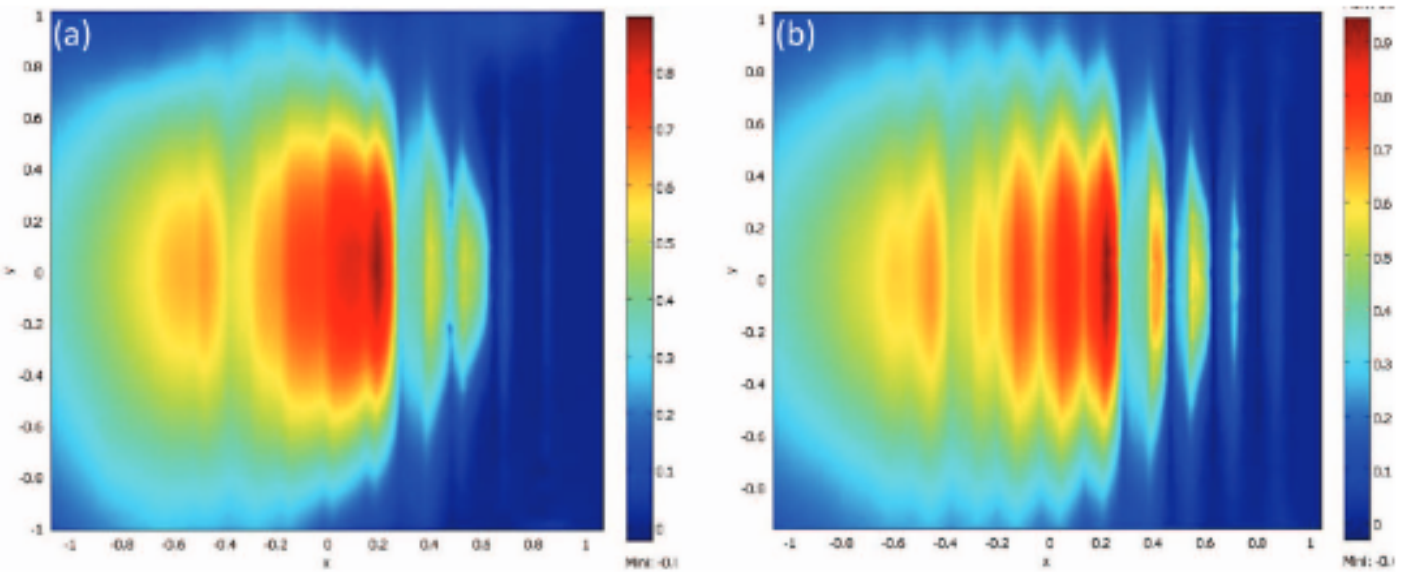

Fig. 6- Pressure field obtained for two surlaces with the same groove depth ( $\left.A_{M}\right)$ and (a) 8-ym (b) 18 pm-seale parameter ( $\left.a_{a s}\right)$ values. (eolor figure available online.)

The generated virtual textured surfaces were used as inputs for the developed contact model. The operating conditions and lubricant parameters are presented in Table 3 .

Figure 6 shows the pressure field obtained with the numerical models defined above. Two different film thicknesses with the same valley depth amplitude and 8 - and 18 - $\mu \mathrm{m}$ scale parameter values were used as the input parameters. The pressure fields were slightly different. The maximum pressure was higher for the low scale parameter (Fig, 6). The increase in seale, corresponding to a larger groove, led to great pressure variations.

Figure 7 shows the friction coefficient map (in percentage) for different values of valley depth amplitude $\left(A_{H}\right)$ and scale parameter $\left(a_{s c}\right)$ and by considering two different groove densities. We can clearly observe the existence of a critical scale parameter value of $a_{\text {sciv }}=12 \mu \mathrm{m}$. Evolution of the friction coefficient differs depending on this critical value:

- Below this critical value $\left(a_{m a x}=12 \mu \mathrm{m}\right)$, the friction coefficient decrease when the valley depth $\left(A_{\mathrm{H}}\right)$ increases. The

increase in valley depth can reduce the friction coefficient by almost $6 \%$ (from 1.65 to $1.55 \%$ ).

- However, above this value, groove depths have a negative effect on the friction coefficient, which is usually observed in the rough contacts (friction increases with increased roughness).

This result is in concordance with the results of some authors who found the existence of an optimum value of the depth-towidth ratio (Costa and Hutchings (4I)). However, there is considerable variation in values reported.

The same evolution was observed when the valley density increased (Fig. 7b). The critical scale value remained the same. This increase in groove density had a beneficial effect on the friction coefficient for low scale parameter values (below $\left(a_{\left(\text {scoel }_{1}\right)}\right)$ compared to low density. However, for high scale parameter values (above $a_{\left(x_{0, e}\right)}$ ), increasing the groove density led to higher friction.
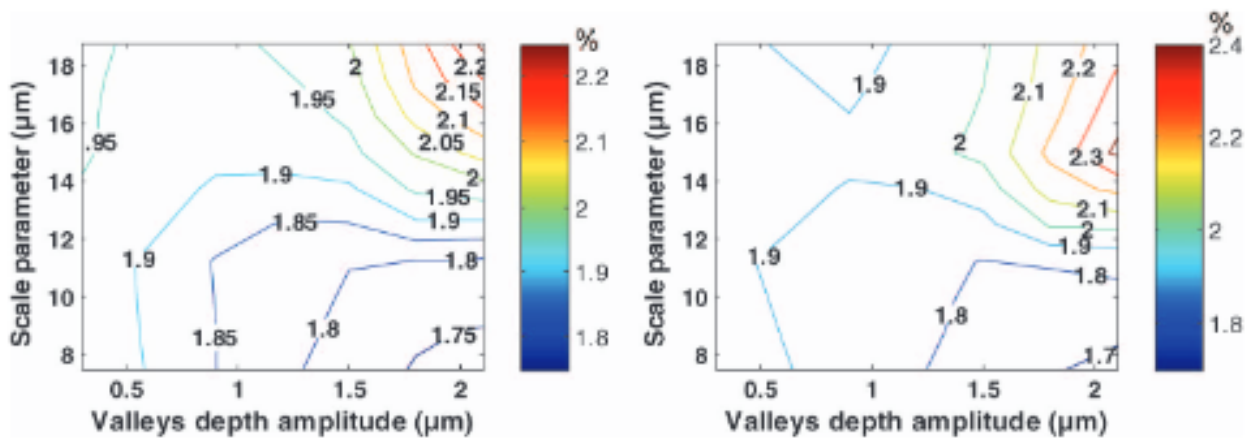

Fig. 7-Efleet of valley seale $a_{s e}$ and depth $A_{m}$ on the triction coeffieient ( $\mathcal{F}_{6}$ ) lor density: (a) $d_{1}$ and (b) $d_{2}$. (color figure available online.) 


\section{CONCLUSIONS}

Finished surfaces are made with a succession of processes using different sizes of abrasive grits from coarser to finer, which leads to surface scale modifications. In this study, advanced characterizations were proposed and applied to investipate the scale effect in elastohydrodynamic contacts. Surface topography can be decomposed into two principal components: superficial roughness and valleys. In this study, superficial roughness was modeled using a fractal model and a scaling factor was introduced to model valley patterns.

The results were as follows:

- A decrease in superficial surface irregularities (increase in Holder exponent) reduces the coefficient of friction.

- There is a critical scale, the effect of valley depth is different on both sides of this critical value, below which the increase in valley depth amplitude can reduce friction.

Finally, in the range of the simulation parameter, the results showed that in EHL contacts at a fine scale, the optimal friction coefficient can be achieved with skewed superficial rough surfaces with high groove depth.

\section{ACKNOWLEDGEMENT}

The authors thank S. Legros for his dedication and computer support during this work.

\section{REFERENCES}

(i) Hamilton, D. B., Walowit, J. A., and Allen, C. M. (1966), "A Theory of Lubrication by Micro-Imegularities," Journal of Rasic Enginceriag, 88, pp $177-185$

c) Etsion, L (2005), "State of the Ant in Laser Surface Texturing," Jourmal of Tribology, 127, pp 245 283.

3) Fullex, K. N. G. and Tabor, D. (1974), "The Effect of Surface Roughnes on the Adhesion of Elastic Solids," Procendings of Royal Socinty A, 42, pp 345-327.

(4) Mexphani, S., Jourani, A, and Zahouani, H. (2006), "The Scale Effect of Roughness in Contact Probbems," High Pefformance Siructures and Mafe rist III Transuction, Brebtes, C. A. (Ed.), pp 369-378, Wessex Institute of Technolopy: Osiend, UK.

6) Zahousen, H, Vargiolu, R., and Loubet, J. L. (1998), "Fractal Models of Surface Topography and Contact Mechaniex," Mathemafis and Compuler Modelling, 28, pp $517-534$.

(6) Majunder, A. and Bhushan, B. (1991), "Fractal Model of Flastic Plastic Contact betwoen Rough Surfaces," Jowrnal of Tribology, 13, pp 1-11.

(7) Ju, Y. and Famris, T. N. (1996), "Spectral Analysis of Two Dimensional Contact Problems," Trunsertions of the ASME, 118, pp $320-300$.

(8) Liu, S, Wang, Q, and Liu, G. (2000), "A Versatile Method of Discrete Coavolution and FFT for Contact Analyses," Wevr, 24, pp 101-111.

0) Gagacpin, J.J. and Roques-Cames, C, (1086), "Fractal Approsch to TwoDimensional and Three-Dimensional Surfsce Roughness," Wear, 109, pp
$119-114$.

(10) Majunder, A and Tien, C L _ (1990), "Fractal Chancterization and Simulation of Rough Surfaces," Wear, 136, pp 313 327.

(ii) Ajay, O. O, Erck, R. A., Loremo-Martin, C, and Fenske, G. R. (2009) Frictional Anisotropy under Boundary Lubrication: Fiffect of Surface Texture," Wear, 267, pp 1214-1219.

(12) Mexphani, S, Demirci, I., Zahouani, H., and Mansori, M. El. (2011), "The Effect of Groove Teature Patterms on Piston Ring Pack Friction," Prect sion Fingihereing, 36(2), Dp 210-217.

(13) Ye, H., Wang, X., and Whou, F. (2010), “Geometric Shape Effect of Sur face Texture on the Generation of Hydrodyamic Pressure hetween Conformal Contacting Surfaces, " Trthology Letters, 37, pp $123-130$.

(14) Nanbe, T, Ren, N, Yasuda, Y, Zhe, D, and Wang, Q. J. (207), "Msco Textures in Concentnated ConformaL Contact Lubrication: Effects of Tex ture Botion Shspe and Surface Relstive Motion," Trublogy Leters, 20, пр $241-252$
(15) Siripuram, R. B. and Stephens, L. S. 2004), "Effect of Determinietic As perity Geometry oe Hydrodyaamic Lubrication," Journal of Truhologr. 126, pp $527-534$

(16) Grotenood, J. A. and Morales-Fspejet, G. E. (1904). The Bettaviour of Transverse Rouphaess in EHL_Contacts," Procomings of the Insfifullow of Mechanical Engineers - Purt J: Jaurnal of Einginecring Trabology, 29, pi $121-132$.

(17) Lugt, P. M. and Morales Espejel, G. E. (2011), "A Review of Blasto Hydrodynamic Labrication Theory," Tribology Transuctlons, 54, pp 400-496.

(18) Wang, J., Venect, C. H, and Lubrecht, A. A. (2011), "Amplitede Reduction in EHL. Line Contacts Rolling Sliding Conditions," Tribology Imier. national, 4(12), pp $1997-2001$

(19) Venner, C. H. and Lubrecht, A. A. (1999), "Amplitude Reductivn of Non-

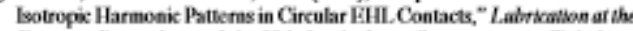
Frowtis, Procosdings of the $25 \mathrm{ch}$ Lents Lyon Symposiam on Tribloge.

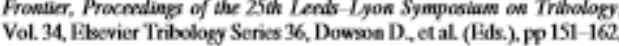
Elecvicr: Lyon, The Netherlands.

(20) Zhu, D. and Hu, Y.Z (2001), "Tffect of Rough Surface Topography and Orientation on the Characteristics of KHD and Mixed Labrication in Both Circular and Filliptical Contacts," Trabogy Travsartions, 44, pp 391-398.

(21) Ryk, G. and Fitsion, I. (2006), "Testing Piston Rings with Partial Laset Surface Texturing for Friction Redaction," Wear, 261, pp T22 - T66.

22) Fxion, I., Halperin, G, Brizer, V., and Kligerman, Y. (2004), "Expen mental Investigation of Laser Sarface Textared Paralle! Thrust Bearings," Tribology Laters, 17, pp 205-300

(23) Kovalchesiko, A, Ajayi, O, Erdemir, A, Fenske, G, and Eision, I. (2006), The Effect of Laser Surface Texturiag on Transitions in Lubrication Regimes daring Unidirextionsal Slifing Contact," Tribology International, 38, DP $219-225$.

24) Krupka, L. and Hartl, M. (2007). The Effect of Surface Teaturing on Thin EHD Luthrication Films," Trabology Intersational, 41, pp 1100-1110.

(2) Wang, Q. I. and Zhe, D. (2005), "Virteal Texturing: Modeling the Perfor mance of Lubricated Contacts of Engineered Serfaces," Jowrnal of Tribl ogy, $127, \mathrm{pp} 727 \mathrm{R}$

(20) Ai, X. and Cheng, H. S. (1996), "The Fffect of Surtace Texture on EHI. Points Contacts, "Journal of Tribology, 118 , pp 5966.

(27) Chen, X., Raja, J., and Simamapalli, S. (1955). "Multiscale Analysis of Fin ginexring Surfaces," International Journal of Machine Tools and Mauufac(ure, $35, \mathrm{pp} 213-238$

(26) Sannaredy, H., Raja, J., and Chen, K. (1008), "Characteriestion of Surface Texture Genernated by Multi-Process Manufacture," Iniernatbanal Journil of Mackine Took and Manufacture, 38, pp 520-536.

(29) Sahri, I, Merghani, S. FI Maroori, M., and Zahouani, H. (2011), "Mw tiseake Study of Finish-Honing Process in Mass Production of Cylindet Liner," Wour, $27(3-4), 00500513$.

(30) Reynoble, O. (1886), "On the Theory of the Lubrication and Its Applica toon to Mr Reauchamp Tower's Fryeriments, Including an Fxperimental toon to Mr Besuctamp Tower's Experiments, Including, an Fxperimental
Determination of the Viscosity of Oliwe Oil," Philesophisal Traveactions of the Royal Society, 177, pp $157-234$.

(3I) Dowson, D. and Hipgineon, G. R. (1966), Elastohydradynemic Labvire tios: Fundamentats of Roller and Gear Lubrication, Pergamon: Oxtord.

(32) Roclands, C. J. A. (1966), Combational Aspects of the Viscosity Temperature Pressure Relationshops of Lubricant OAf, Doctoral Thesis, Technische Hopeschot, Delft, The Netherlands.

(33) Liu, Y., Wang, Q. J., Zhu, D., Wane, W., and Hu, Y. (2009), "Effects of Differential Scheme snd Visoceity Model on Rough-Surface Point-Contact Evothermal Fill." Jowroul of Tribology, 131, pp 044501-1-046501-5.

(34) Venacs, C. H. and Lubrocht, A. A. (2000), Multilend Methods in Labrice non, Fbevier. Amsterdam, The Netherlands.

(3) He, Y. Z and Zhe, D. (2000), "A Full Nemerical Solution to the Mised Lubrication in Point Contacts," Journul of Tribology, 122, pp 1-9.

(36) Zhe, D. (2007), "On Some Aspects of Numerical Solutions of Thin Film and Maed Elestohydeodynamic Lubrication," Procoedinges of the Insium.

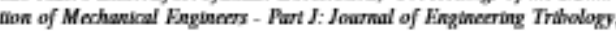
$221, p \rho 561-579$

(37) Chapkov, A (2006), Fude des Contects Flasiohydrodynamigue Labrifies avec un Fuide now Newtonien, Doctoral Thesis, INSA de Lyon, Franos.

(38) Decenciere, E. and Jeulin, D. (2001), "Mophobogical Deoompasition of the Surface Topography of an Internal Combustion Engine Cylinder to the Surface Topography of an Internal Com
Charscterize Wear," Wear, 239, $50,4 \% 2,48$.

(99) Felder, J. (1985), Frocksts, Plenum Pres: New York

(46) Mandetbrot, B. and Van Ness, J. W. (1968), "Fractionsl Beowaian Meborr, Fractivaal Noises, and Applications," SILM Roview, 10, pp 422.437

(4I) Costa, H. Ln and Hutchings, L M. (0007), "Hydrodynamix Lubrication of Texturod Steel Surfaces under Recipeocating Sliding Conditions, " Truhol ogy international 46, pp 1227-1238 